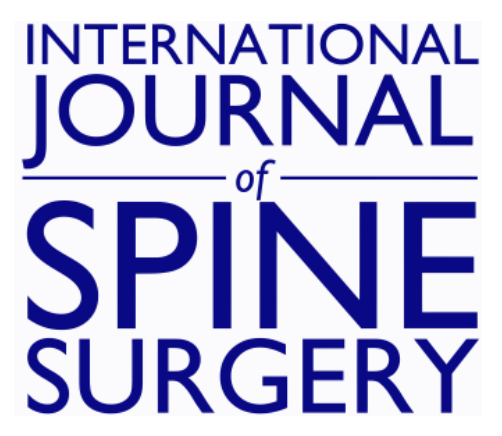

\title{
Safety and Efficacy of Balloon Kyphoplasty for Vertebral Fractures With Posterior Wall Disruption
}

Jennifer L. Perez, Alp Ozpinar, Nitin Agarwal, Emily Hacker, NIMA Alan and Peter C. Gerszten

Int J Spine Surg 2021, 15 (2) 353-358

doi: https://doi.org/10.14444/8046

http://ijssurgery.com/content/15/2/353

This information is current as of April 25, 2023.

Email Alerts Receive free email-alerts when new articles cite this article. Sign up at:

http://ijssurgery.com/alerts

The International Journal of Spine Surgery

2397 Waterbury Circle, Suite 1,

Aurora, IL 60504, Phone: +1-630-375-1432 


\title{
Safety and Efficacy of Balloon Kyphoplasty for Vertebral Fractures With Posterior Wall Disruption
}

\author{
JENNIFER L. PEREZ, PHD, ALP OZPINAR, MD, NITIN AGARWAL, MD, EMILY HACKER, BS, NIMA \\ ALAN, MD, PETER C. GERSZTEN, MD, MPH \\ Department of Neurological Surgery, University of Pittsburgh Medical Center, Pittsburgh, Pennsylvania
}

\begin{abstract}
Background: Percutaneous balloon kyphoplasty (BK) is widely accepted as both a safe and effective method for the treatment of symptomatic benign vertebral compression fractures ( $\mathrm{VCFs}$ ) of the thoracic and lumbar spines. A disruption in the posterior wall of the affected vertebra is often considered to be a relative or an absolute contraindication to BK. This study was performed to determine the safety as well as the efficacy of BK for vertebral body compression fractures associated with posterior wall disruption.

Methods: This was a retrospective, nonrandomized clinical cohort investigation of patients with VCF and posterior wall disruption treated with BK between 2010 and 2018. All cases were performed using a bipedicular technique. Each case was examined for cement leakage, anterior vertebral body height restoration, improvement in pain (determined by VAS) from baseline and 6-week postprocedure, and clinical sequelae from cement leakage.

Results: Ninety-eight consecutive patients with $157 \mathrm{VCF}$ levels who underwent BK were evaluated. There was a significant improvement in anterior vertebral height, vertebral wedge angle, and local kyphotic angle in all cases. The mean preoperative VAS improved from 8.7 preprocedure to 2.5 postprocedure $(P=.001)$. There were $14(9 \%)$ cases with asymptomatic cement leakage outside of the vertebral body, and no patients experienced postprocedure neurological symptoms at the 6-week follow up.

Conclusions: BK in the setting of posterior wall disruption was found to be a safe and highly effective treatment for patients with benign compression fractures. Posterior wall disruption should not be considered an absolute contraindication to BK.
\end{abstract}

Other \& Special Categories

Keywords: cement augmentation, osteoporosis, spine fracture, vertebral compression fracture, vertebroplasty

\section{INTRODUCTION}

Vertebral compression fractures (VCFs) pose a significant health problem, affecting an estimated 700000 patients in the United States each year. Approximately $85 \%$ of VCFs are caused by primary osteoporosis, while the remainder are due to secondary osteoporosis or malignancies. ${ }^{1}$ Regardless of the etiology, loss of height from VCFs leads to progressive sagittal spinal deformity and kyphosis of the thoracic and lumbar spine, resulting in many morbidities including chronic pain, spinal stenosis and deformity, decreased lung capacity, and an overall decreased quality of life. ${ }^{2}$

Traditional treatments for VCFs included conservative nonsurgical medical treatments (NSTs) such as physical therapy, bed rest, various analgesic agents, and back braces to reduce symptoms. ${ }^{3}$ However, NSTs fail to restore spinal alignment and can increase the rate of demineralization, thereby causing persistent, intractable pain or neurological deterioration that requires invasive interventions in some patients. ${ }^{2,4}$

Percutaneous vertebroplasty (PVP) and percutaneous balloon kyphoplasty (BK) are widely used transpedicular cement augmentation procedures used in the surgical management of VCFs. PVP involves forced injection of low viscosity polymethylmethacrylate (PMMA) cement into the closed space of the collapsed vertebral body. ${ }^{5}$ While PVP has been shown to have significant benefit over NSTs, ${ }^{6,7}$ authors of other studies have questioned these results. ${ }^{8,9}$ The PVP procedure fails to restore vertebral body height and correct spinal deformities and is associated with cement leakage rates as high as $65 \%$ in VCFs from metastases and $30 \%$ osteoporotic VCFs. ${ }^{10,11}$

$\mathrm{BK}$ is a procedure that reduces pain and, in some cases, may correct kyphosis secondary to collapsed vertebral bodies. ${ }^{11,12} \mathrm{BK}$ involves insertion of an 

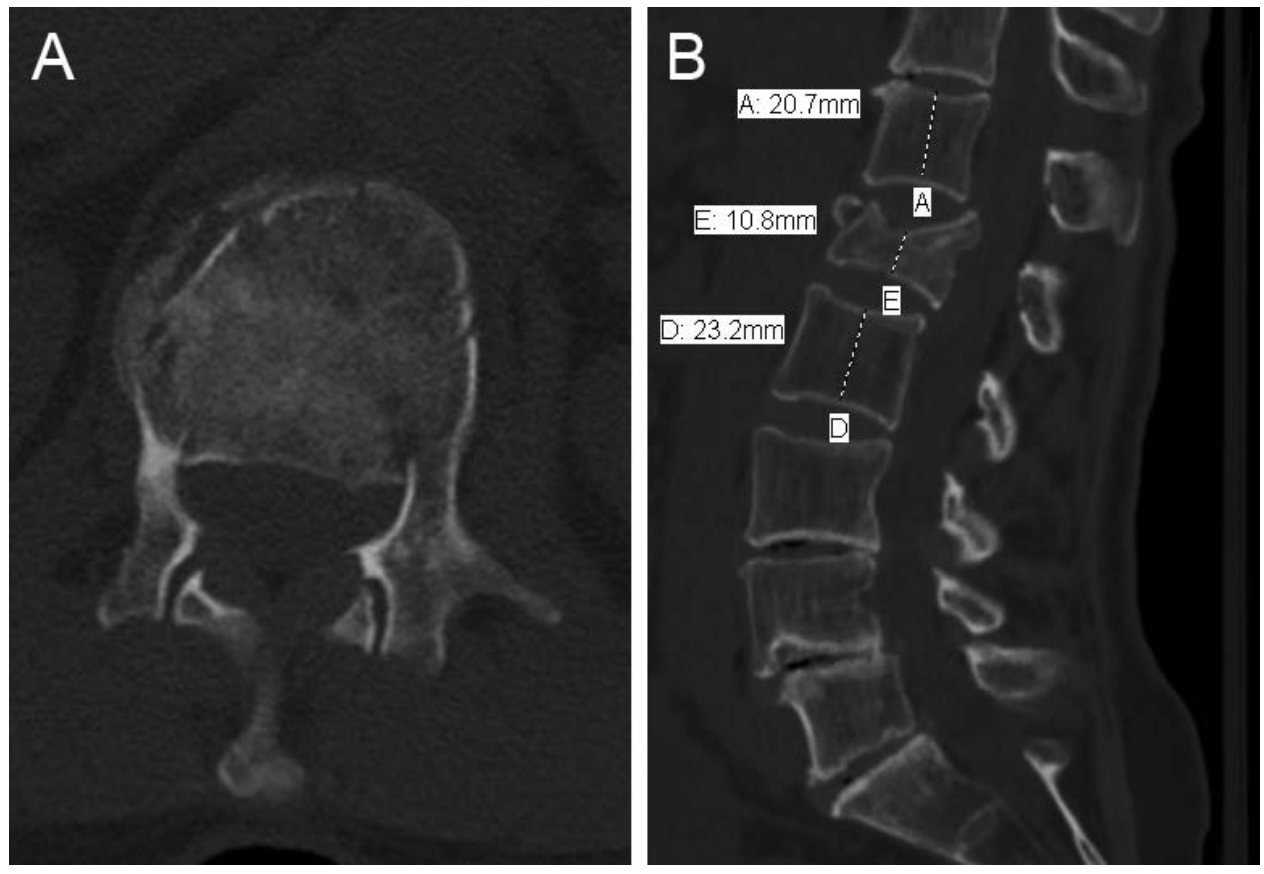

Figure 1. Preoperative computed tomography scan demonstrating 2 column fractures with posterior wall defect. (A) Axial view of L1 vertebra. (B) Sagittal view of lumbar spine with vertebral body height.

inflatable bone tamp into the fractured vertebral body for endplate elevation followed by fixation of the fracture with bone cement. This allows cement augmentation to be performed under a more controlled, low-pressure environment that reduces the risk of cement extravasation. This technique therefore has the advantage of vertebral body height restoration and possible decreased complications resulting from cement leakage. ${ }^{13,14}$ However, posterior vertebral body wall (PVBW) involvement is considered by many clinicians a relative or absolute contraindication for $\mathrm{BK} .{ }^{15,16}$

This study was performed to evaluate the safety and efficacy of BK for benign VCFs associated with posterior wall disruption. If $\mathrm{BK}$ were shown to be safe as well as effective in patients with PVBW defects, it may potentially alleviate the need for more invasive procedures and the associated complications in this patient population.

\section{MATERIALS AND METHODS}

\section{Patient Selection}

From January 2010 to January 2018, 98 consecutive patients (157 VCF levels) who underwent a BK procedure in our hospital for unrelieved back pain from osteoporotic fractures and/or minor trauma leading to compression fractures (Figure 1) were included in this study. All patients were aged
65 years and older and had fractures in the thoracic or lumbar vertebrae with preoperative computed tomography (CT)-confirmed posterior wall disruption and demonstrated evidence of vertebral body edema based upon magnetic resonance imaging (MRI; acute or subacute fractures). Patients with metastatic spinal fractures, neurological deficits, and patients who had not undergone appropriate conservative, nonsurgical treatment were excluded from the study.

\section{Surgical Procedure}

All patients underwent general anesthesia in the prone position. A single C-arm was used for fluoroscopic guidance. Bipedicular access was obtained percutaneously in all cases (Figure 2). The Kyphon Express II (Medtronic Spinal and Biologics, Memphis, Tennessee) kit was used for all procedures. Balloons were inserted into the central anterior two-thirds of the vertebral body. Balloons were dilated appropriately and terminated when the balloon approached the subchondral plate (Figure 3). After balloon removal, high-viscosity bariumopacified PMMA cement was infused (Figure 4; Kyphon Xpede bone cement, Medtronic Spine LLC, Sunnyvale, California). To ensure there is no cement leakage, the cement is made particularly thick before injections, and a series of intraoperative 

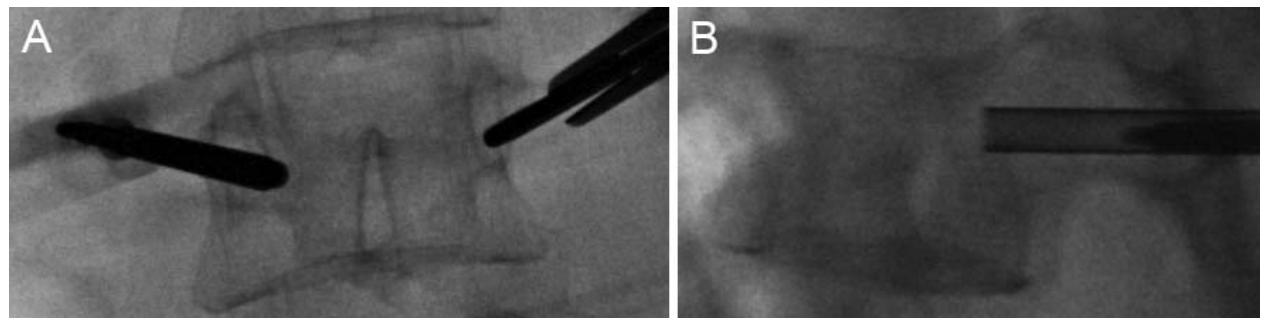

Figure 2. Intraoperative fluoroscopic image demonstrating bipedicular approach.

images are taken to make sure no cement leakage is present in the posterior one-third of vertebral body.

\section{Outcomes}

Functional outcomes were assessed preoperatively and at 6 weeks. Pain (average back pain in the past week) was assessed subjectively using a visual analog score (VAS) from 0 (no pain) to 10 (worst pain imaginable).

Standing anteroposterior and lateral spine radiographs were obtained preoperatively and intraoperatively before conclusion of the procedure. Anterior vertebral body height (AVBH), local kyphotic angle, and vertebral wedge angle (VWA) were calculated preoperatively and intraoperatively. Local kyphotic angle was defined as the angle formed by lines drawn at a $90^{\circ}$ to the lines parallel to the most caudal and cranial fractured vertebral body endplates. All measurements were made directly on scan using the institutional electronic image viewer.

Cement leakage was assessed via intraoperative fluoroscopic images. Complications, including mortality and neurological deficits, were assessed at 6 weeks postoperatively.

\section{Statistical Analysis}

Statistical analysis was performed using IMB SPSS Statistics (SPSS Inc., Chicago, Illinois). Descriptive statistics were generated using independent sample $t$ tests for continuous variables.
Statistical significance was accepted at a $P$ value of $<.05$.

\section{RESULTS}

Patient demographics are outlined in Table 1. Ninety-eight consecutive patients (52 [53\%] female; 46 [47\%] male) with 157 levels of BK were identified to fit the inclusion criteria. Mean body mass index (BMI) was $28.2( \pm 8.3)$. Ninety-four levels were in the thoracic spine, and 63 were in the lumbar spine. Patients were divided into 2 groups: Group 1 included those who underwent BK at levels T2-L2 (121 levels), and group 2 included those who underwent BK at levels L3-L5 (36 levels); this categorization is consistent with that performed in previous studies. ${ }^{17,18}$ The upper lumbar vertebrae (L1, L2) were grouped with the thoracic vertebrae, given their similarity in alignment with the thoracic spine.

The results of this study are summarized in Table 2. In group 1, the mean AVBH was $16.4( \pm 4.4) \mathrm{mm}$ preprocedure and $21.3( \pm 5.3) \mathrm{mm}$ postprocedure $(P$ $=.001)$. Mean VWA improved from $9.8( \pm 4.9)$ to 4.7 ( \pm 3.1$)$. Mean preoperative kyphotic angle improved from $13.3( \pm 10.6)$ to $8.8( \pm 10.9)$. In group 2, the mean AVBH was $24.6( \pm 5.4) \mathrm{mm}$ preprocedure and $26.5( \pm 4.3) \mathrm{mm}$ postprocedure $(P$ $=.001$; Figure 5). Mean VWA improved from 3.6 $( \pm 4.7)$ to $1.1( \pm 5.4)$. Mean preoperative kyphotic
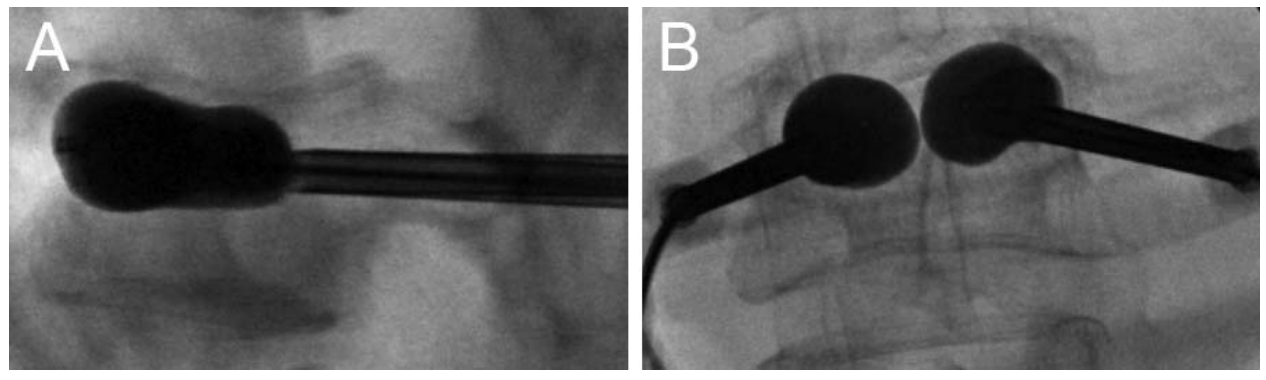

Figure 3. Sequential balloon dilation in bipedicular fashion. (A) Lateral and (B) Anterior-Posterior fluoroscopic views showing good endplate reduction and improvement of anterior vertebral height intraoperatively. 

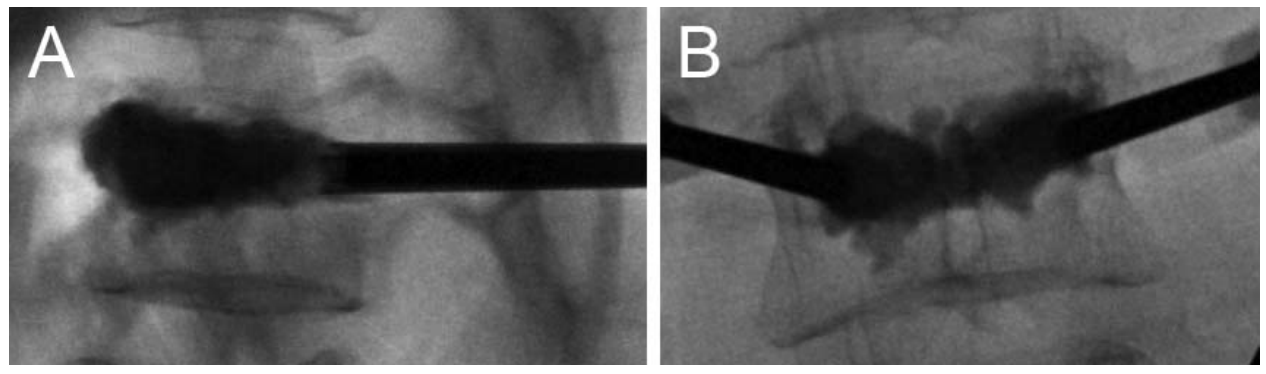

Figure 4. Fluoroscopic image demonstrating cement filling at the conclusion of the case prior to trocar removal. (A) Lateral and (B) Anterior-Posterior views showing cement filling with no leakage.

Table 1. Patient demographics and characteristics.

\begin{tabular}{|c|c|}
\hline Variable & Data \\
\hline \multicolumn{2}{|l|}{ Group 1 (T2-L2) } \\
\hline No. & 121 levels \\
\hline Median age (range) & $64(60-85)$ \\
\hline Mean $( \pm$ SD) BMI & $28.4( \pm 5.3)$ \\
\hline No. lumbar levels & 34 \\
\hline No. thoracic levels & 87 \\
\hline \multicolumn{2}{|l|}{ Group 2 (L3-L5) } \\
\hline No. & 36 levels \\
\hline Median age (range) & $61(60-84)$ \\
\hline Mean $( \pm \mathrm{SD}) \mathrm{BMI}$ & $27.4( \pm 7.5)$ \\
\hline \multicolumn{2}{|l|}{ Overall } \\
\hline No. & 98 patients, 157 levels \\
\hline Median age (range) & $69(60-85)$ \\
\hline Mean $( \pm$ SD) BMI & $28.2( \pm 8.3)$ \\
\hline No. lumbar levels & 70 \\
\hline No. thoracic levels & 87 \\
\hline
\end{tabular}

Abbreviations: BMI, body mass index; SD, standard deviation.

Table 2. Summary of radiographic results. Measurements in millimeters.

\begin{tabular}{|c|c|c|c|}
\hline Variable & Preoperative & Postoperative & $P$ Value \\
\hline \multicolumn{4}{|l|}{ Group A } \\
\hline Mean kyphotic angle $( \pm \mathrm{SD})$ & $13.3( \pm 10.6)$ & $8.8( \pm 10.9)$ & .02 \\
\hline Mean $( \pm S D)$ VWA & $9.8( \pm 4.9)$ & $4.7( \pm 3.1)$ & .01 \\
\hline Mean $( \pm$ SD) AVH & $16.4( \pm 4.4)$ & $21.3( \pm 5.3)$ & $.001^{\mathrm{a}}$ \\
\hline \multicolumn{4}{|l|}{ Group B } \\
\hline Mean kyphotic angle $( \pm S D)$ & $-11.5( \pm 18.4)$ & $-14.4( \pm 16.5)$ & .03 \\
\hline Mean $( \pm$ SD) VWA & $3.6( \pm 4.7)$ & $1.1( \pm 5.4)$ & .02 \\
\hline Mean $( \pm$ SD) AVH & $24.6( \pm 5.4)$ & $26.5( \pm 4.3)$ & $.001^{\mathrm{a}}$ \\
\hline
\end{tabular}

Abbreviations: AVH, anterior vertebral height; SD, standard deviation; VWA, vertebral wedge angle.

${ }^{a} P$ value considered statistically significant $(P<.05)$.
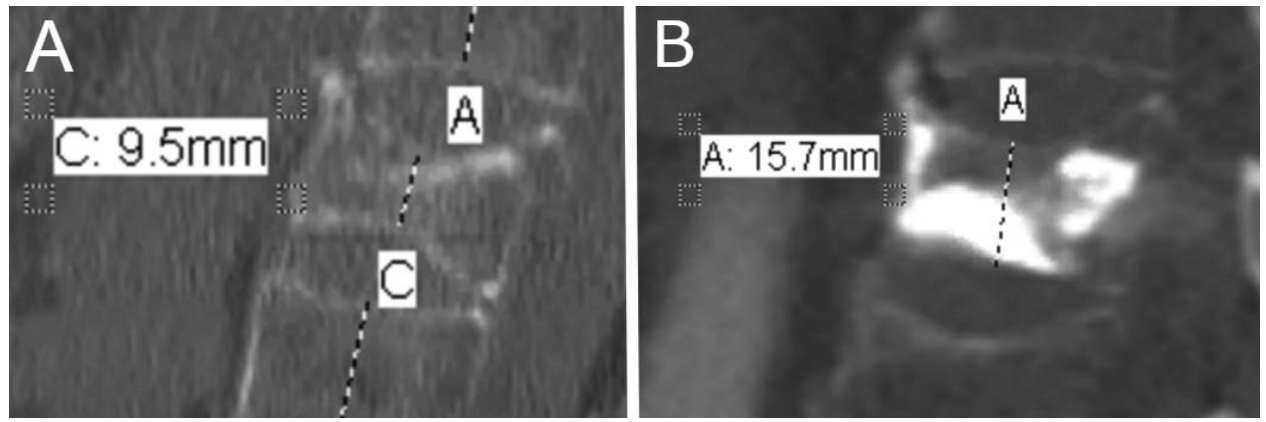

Figure 5. Sagittal computed tomography scan demonstrating maintenance of improvement in lumbar spine vertebral body height from (A) preoperative to (B) 2 years postoperatively. angle improved from $-11.5( \pm 18.4)$ to -14.4 ( \pm 16.5$)$.

Overall, in both groups 1 and 2, the mean VAS improved from 8.7 preprocedure to 2.5 postprocedure $(P=.001)$. Finally, there were $14(9 \%)$ cases with asymptomatic cement leakage outside of the vertebral body. No patients developed new neurological symptoms after BK.

\section{DISCUSSION}

BK has become a frequently performed, minimally invasive spinal surgical procedure and is considered a safe and effective treatment for benign osteoporotic or traumatic VCFs. However, PVBW defects are considered a relative or absolute contraindication for $\mathrm{BK}^{15,16,19}$ due to the threat that balloon inflation may force fragments into the spinal canal, or posterior cement leakage may occur during PMMA insertion. This study demonstrated that BK in the setting of PVBW defects was associated with improvement in pain, increased postoperative vertebral body height, and correction of kyphosis. Furthermore, no patient developed new neurological symptoms after surgery because of cement leakage.

Osteoporotic or trauma-induced compressions fractures commonly result in spinal deformity such 
as kyphosis, resulting from increased sagittal plane deformity, which causes biomechanical stress on the spine. This kyphosis can cause intractable pain, spinal canal stenosis, and neurological symptoms that may require surgical intervention. Further, it has been suggested that PVBW defects may result in greater postoperative progression of vertebral collapse than those with endplate or anterior wall damage alone. ${ }^{20,21}$ However, BK has been recommended as the most appropriate treatment of VCFs in the majority of clinical scenarios. ${ }^{22,23}$ Indeed, in a prospective study of patients with VCF, Maestretti et $\mathrm{al}^{18}$ found no loss of correction of the vertebral and segmental kyphosis angle at 10 years postprocedure. Furthermore, Abdelgawaad et $\mathrm{al}^{17}$ reported an improvement in both the vertebral angle and vertebral body height in patients with VCF complicated by PVBW defect. In agreement with these results, we found no loss of corrected vertebral height or loss of the corrected kyphotic angles at the 6-week follow up compared with the immediate postoperative period.

Cement leakage is considered one of the most common serious complications of $\mathrm{BK}$, and the risk is thought to be higher in the presence of a PVBW defect. This could be a result of the anterior and posterior longitudinal ligaments acting as a physical barrier to limiting or preventing cement leakage during balloon inflation. However, in 1 study using human cadaveric burst fracture models, traumatic ligamentous and bony damage did not significantly increase the frequency or amount of cement

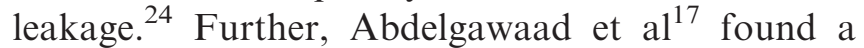
$22.5 \%$ asymptomatic leakage (cortical, diskal, or vascular) rate in a prospective study of 82 patients with traumatic VCF and PVBW defects. Importantly, they found no leakage of cement into the spinal canal in any case. ${ }^{17}$

In addition, intraoperative cement extravasation may cause serious neurological injury or pulmonary cement embolism. While only a few case reports have documented neurological injuries, the incidence of pulmonary cement embolism is estimated to be between $3 \%$ and $23 \%$, though the majority had no clinical significanc. ${ }^{25,26}$ In the current study, no patients experienced intraoperative pulmonary cement embolism. Rarely, postoperative symptomatic cement leakage may occur and have serious neurologic complications such as worsening pain, radiculopathy, spinal cord compression, or cauda equina compression. ${ }^{27,28}$ In the current study, 14
$(9 \%)$ of patients experienced postoperative cement leakage. However, all cases of cement leakage were asymptomatic, and no patients experienced pulmonary cement embolism or any new neurological deficits. These findings are consistent with Abdelgawaad et al, ${ }^{17}$ who also found no pulmonary cement embolism or neurologic complications after cement leakage in patients with traumatic VCF complicated by PVBW defects. Future studies may use advanced imaging modalities to address the inherent limitations of using fluoroscopy to detect cement leakage and cement embolism.

\section{CONCLUSIONS}

This study supports the safety and efficacy of BK for the management of benign VCFs in the setting of a PVBW defect. Although posterior wall defects were previously considered a relative or absolute contraindication to $\mathrm{BK}$ in patients with benign vertebral wall compression fractures, carefully selected patients ${ }^{29}$ can still achieve a high level of clinical success and safety using BK in this relatively common clinical setting.

\section{REFERENCES}

1. Cooper C, Atkinson EJ, O'Fallon WM, Melton LJ 3rd. Incidence of clinically diagnosed vertebral fractures: a population-based study in Rochester, Minnesota, 1985-1989. J Bone Miner Res. 1992;7(2):221-227.

2. Heaney RP. The natural history of vertebral osteoporosis. Is low bone mass an epiphenomenon? Bone. 1992;13 Suppl 2:S23-S26.

3. Malmivaara A, Hakkinen U, Aro T, et al. The treatment of acute low back pain-bed rest, exercises, or ordinary activity? N Engl J Med. 1995;332(6):351-355.

4. Kanis JA, McCloskey EV, Powles T, Paterson AH, Ashley S, Spector T. A high incidence of vertebral fracture in women with breast cancer. Br J Cancer. 1999;79(7-8):11791181 .

5. Galibert $\mathrm{P}$, Deramond $\mathrm{H}$, Rosat $\mathrm{P}$, Le Gars D. [Preliminary note on the treatment of vertebral angioma by percutaneous acrylic vertebroplasty]. Neurochirurgie. 1987;33(2):166-168.

6. Diamond TH, Bryant C, Browne L, Clark WA. Clinical outcomes after acute osteoporotic vertebral fractures: a 2-year non-randomised trial comparing percutaneous vertebroplasty with conservative therapy. Med J Aust. 2006;184(3):113-117.

7. Klazen CA, Lohle PN, de Vries J, et al. Vertebroplasty versus conservative treatment in acute osteoporotic vertebral compression fractures (Vertos II): an open-label randomised trial. Lancet. 2010;376(9746):1085-1092.

8. Buchbinder R, Osborne RH, Ebeling PR, et al. A randomized trial of vertebroplasty for painful osteoporotic vertebral fractures. $N$ Engl J Med. 2009;361(6):557-568.

9. Kallmes DF, Comstock BA, Heagerty PJ, et al. A 
randomized trial of vertebroplasty for osteoporotic spinal fractures. N Engl J Med. 2009;361(6):569-579.

10. Jensen ME, Evans AJ, Mathis JM, Kallmes DF, Cloft HJ, Dion JE. Percutaneous polymethylmethacrylate vertebroplasty in the treatment of osteoporotic vertebral body compression fractures: technical aspects. AJNR Am J Neuroradiol. 1997;18(10):1897-1904.

11. Lieberman IH, Dudeney S, Reinhardt MK, Bell G. Initial outcome and efficacy of "kyphoplasty" in the treatment of painful osteoporotic vertebral compression fractures. Spine (Phila Pa 1976). 2001;26(14):1631-1638.

12. Garfin SR, Yuan HA, Reiley MA. New technologies in spine: kyphoplasty and vertebroplasty for the treatment of painful osteoporotic compression fractures. Spine (Phila $\mathrm{Pa}$ 1976). 2001;26(14):1511-1515.

13. Van Meirhaeghe J, Bastian L, Boonen S, et al. A randomized trial of balloon kyphoplasty and nonsurgical management for treating acute vertebral compression fractures: vertebral body kyphosis correction and surgical parameters. Spine (Phila Pa 1976). 2013;38(12):971-983.

14. Wardlaw D, Cummings SR, Van Meirhaeghe J, et al. Efficacy and safety of balloon kyphoplasty compared with nonsurgical care for vertebral compression fracture (FREE): a randomised controlled trial. Lancet. 2009;373(9668):1016-1024.

15. Mueller CW, Berlemann U. Kyphoplasty: chances and limits. Neurol India. 2005;53(4):451-457.

16. Saxena BP, Shah BV, Joshi SP. Outcome of percutaneous balloon kyphoplasty in vertebral compression fractures. Indian J Orthop. 2015;49(4):458-464.

17. Abdelgawaad AS, Ezzati A, Govindasamy R, Krajnovic B, Elnady B, Said GZ. Kyphoplasty for osteoporotic vertebral fractures with posterior wall injury. Spine J. 2018;18(7):11431148 .

18. Maestretti G, Sutter P, Monnard E, et al. A prospective study of percutaneous balloon kyphoplasty with calcium phosphate cement in traumatic vertebral fractures: 10-year results. Eur Spine J. 2014;23(6):1354-1360.

19. Zhao L, Xu R, Hu T, Ma W, Xia H, Wang G. Quantitative evaluation of the location of the vertebral artery in relation to the transverse foramen in the lower cervical spine. Spine (Phila Pa 1976). 2008;33(4):373-378.

20. Ha KY, Kim YH, Chang DG, Son IN, Kim KW, Kim SE. Causes of late revision surgery after bone cement augmentation in osteoporotic vertebral compression fractures. Asian Spine J. 2013;7(4):294-300.

21. Kanchiku T, Taguchi T, Kawai S. Magnetic resonance imaging diagnosis and new classification of the osteoporotic vertebral fracture. J Orthop Sci. 2003;8(4):463-466.

22. Anselmetti GC, Bernard J, Blattert T, et al. Criteria for the appropriate treatment of osteoporotic vertebral compression fractures. Pain Physician. 2013;16(5):E519-E530.

23. Schupfner R, Stoevelaar HJ, Blattert T, et al. Treatment of osteoporotic vertebral compression fractures: applicability of appropriateness criteria in clinical practice. Pain Physician. 2016;19(1):E113-E120.

24. Oner FC, Verlaan JJ, Verbout AJ, Dhert WJ. Cement augmentation techniques in traumatic thoracolumbar spine fractures. Spine (Phila Pa 1976). 2006;31(11 Suppl):S89-S95; discussion S104.

25. Krueger A, Bliemel C, Zettl R, Ruchholtz S. Management of pulmonary cement embolism after percutaneous vertebroplasty and kyphoplasty: a systematic review of the literature. Eur Spine J. 2009;18(9):1257-1265.

26. Walter J, Haciyakupoglu E, Waschke A, Kalff R, Ewald C. Cement leakage as a possible complication of balloon kyphoplasty - is there a difference between osteoporotic compression fractures (AO type A1) and incomplete burst fractures (AO type A3.1)? Acta Neurochir (Wien). 2012;154(2):313-319.

27. Kasperk C, Hillmeier J, Noldge G, et al. Treatment of painful vertebral fractures by kyphoplasty in patients with primary osteoporosis: a prospective nonrandomized controlled study. J Bone Miner Res. 2005;20(4):604-612.

28. Lee ST, Chen JF. Closed reduction vertebroplasty for the treatment of osteoporotic vertebral compression fractures. Technical note. J Neurosurg. 2004;100(4 Suppl Spine):392-396.

29. Hirsch JA, Beall DP, Chambers MR, et al. Management of vertebral fragility fractures: a clinical care pathway developed by a multispecialty panel using the RAND/UCLA Appropriateness Method. Spine J. 2018;18(11):2152-2161.

Disclosures and COI: Data from this study was presented at the 35 th Annual Meeting of the AANS/CNS Section on Disorders of the Spine and Peripheral Nerves, Spine Summit, Miami, FL, March 14-17, 2019. The authors received no funding for this study and report no conflicts of interest.

Corresponding Author: Peter C. Gerszten, MD, MPH, Department of Neurological Surgery, University of Pittsburgh Medical Center, 200 Lothrop Street, Suite B-400, Pittsburgh, PA 15213-2582. Phone: (412) 647-3685; Email: gerspc@upmc.edu.

Published 16 April 2021

This manuscript is generously published free of charge by ISASS, the International Society for the Advancement of Spine Surgery. Copyright (C) 2021 ISASS. To see more or order reprints or permissions, see http://ijssurgery.com. 